\title{
Which Elections Can Be Lost?
}

\author{
Susan D. Hyde and Nikolay Marinov \\ Department of Political Science, Yale University, New Haven, CT 06520 \\ e-mail: susan.hyde@yale.edu (corresponding author),nikolay.marinov@yale.edu
}

Edited by Vera Troeger

\begin{abstract}
The concept of electoral competition is relevant to a variety of research agendas in political science, yet the question of how to measure electoral competition has received little direct attention. We revisit the distinction proposed by Giovanni Sartori between competition as a structure or rule of the game and competitiveness as an outcome of that game and argue that to understand which elections can be lost (and therefore when parties and leaders are potentially threatened by electoral accountability), scholars may be better off considering the full range of elections where competition is allowed. We provide a data set of all national elections between 1945 and 2006 and a measure of whether each election event is structured such that the competition is possible. We outline the pitfalls of other measures used by scholars to define the potential for electoral competition and show that such methods can lead to biased or incomplete findings. The new global data on elections and the minimal conditions necessary for electoral competition are introduced, followed by an empirical illustration of the differences between the proposed measure of competition and existing methods used to infer the existence of competition.
\end{abstract}

\section{Introduction}

Elections occur across regime types, motivating a rich theoretical literature on countries that "inhabit the wide and foggy zone between liberal democracy and closed authoritarianism" (Schedler 2002, 37). Yet this literature has been limited by a measurement problem. To date, scholars have not agreed on criteria that define which elections can be lost. This is important because it represents the appropriate universe of cases for many research questions in the field. Many scholars either avoid cross-national research on electoral competition because of problems with data quality or use criteria that allow for post hoc adjustments to the universe of countries included in the analysis. To put the problem starkly, if scholars are interested in studying the consequences of elections, they should not exclude elections based on whether they were consequential. Doing so excludes all cases of elections that could have been consequential but were not, and as we show, risks producing biased estimates of parameters of interest.

Despite growing interest in the diffusion of elections across regime types, professional incentives for data provision by scholars are low within political science, and many data sets are used uncritically. For example, Gerardo Munck and Jay Verkuilen summarize dominant methodological approaches in the study of democracy and argue that "problems of causal inference have overshadowed the equally important problems of conceptualization and measurement" (Munck and Verkuilen 2002, 5-6). Similarly, Yoshiko Herrera and Devesh Kapur complain that "inattentiveness to data quality is, unfortunately, business as

Authors' note: We thank the MacMillan Center for International and Area Studies, the Institution for Social and Policy Studies, and the Jackson Institute at Yale University for generous support of this project. For helpful comments on previous drafts, we thank Sarah Bush, Marc Howard, Alex Kuo, Patrick Kuhn, Ellen Lust, Irfan Nooruddin, Angela O'Mahony, Kennedy Opalo, Philip Roessler, Nils Weidmann, seminar participants at the College of William \& Mary, participants at the 2010 meeting of the Midwest Political Science Conference, the 2011 American Political Science Association, and attendees at the Juan March Institute's 2011 Conference on Electoral Fraud, Vote Buying, and Clientelism. Our gratitude goes to our team of excellent research assistants: Spencer Allee, William Brien, Faizan Diwan, Michael Fan, Josiane Gabel, Martha Grant, Michael Haycock, Allison Hugi, Shazan Jiwa, Bryce Kaufman, Adam Kinnon, Marianna Lanzas Goded, Vanessa Murphy, Ja-Mei Or, Jane Park, Ajla Porca, Karen Porter, Steven Rosenzweig, Gordon Siu, Mary Swartz, Peter Swartz, Rey-Hanna Vakili, Jared Webber, Jerome Wei, Lucas Wozny, Miaoting $\mathrm{Wu}$, and Jiaona Zhang. 
usual in political science" (Herrera and Kapur 2007, 366). The incentives against systematic collection of cross-national data are large, and there are strong motivations for scholars to use off-the-shelf data and justify it as the "best available." Herrera and Kapur complain that such dynamics mean that many "data are used because they are used-and the data sets, problematic or not, become acceptable by repetition" (Herrera and Kapur 2007, 382). In response to a similar problem in the study of elections across regime types, we seek to provide a more transparent and precise measure of elections and their potential for competition.

In this article, our aim is not to undercut studies that have already been published, but to clearly define the measurement problem, provide a solution to it, and demonstrate why a direct measure of the potential for electoral competition is substantively important in future research.

Our measure of electoral competition is based on three criteria: whether opposition is allowed, multiple parties are legal, and more than one candidate competes. All elections that meet all three criteria are defined as elections with competition. Note that our goal is not to predict which elections will be lost nor to propose an alternative measure of regime type. Rather, we define and measure which elections could be lost, thus providing the full universe of potentially competitive elections. This measure is intentionally minimalist and can be used as a baseline for scholars interested in studying the role that other factors, such as election fraud, opposition coordination, electoral rules, or media bias, play in the causes and consequences of electoral competition. The data introduced in this article cover all direct elections for national office, which includes all 157 independent states with a population greater than 500,000 that held at least one national election between 1945 and $2006 .{ }^{1}$

This proposed measure has several advantages over existing approaches. First, it is defined ex ante without attention to the actual performance of candidates in the election. This distinction is crucial for studies that seek to understand the conditions under which elections are likely to be lost, as excluding elections based on the outcome of elections adds bias to hypothesis testing. Second, it can be applied across regime types, which sidesteps a common problem in which researchers attempt to study the determinants of political change by using complex and potentially endogenous measures of regime type. Third, by providing an overtly minimalist definition of electoral competition, it draws a bright line between elections in which a government loss is possible and those in which it is impossible.

The method used to define the universe of relevant elections has substantively important consequences, which we demonstrate in relation to how media bias influences election competitiveness. In addition to our empirical illustration, there are a number of research questions for which more complete data on elections and competition could be useful. Existing scholarship includes many examples: Do repeated elections lead to democratization (Lindberg 2006a)? Does even minimal electoral competition in African countries induce fiscal manipulation (Block, Ferree, and Singh 2003)? Do democratic institutions, including potentially competitive elections, increase foreign direct investment or deter it (Jensen 2003)? Does electoral competition (and more generally, democracy) lead governments to be more transparent (Hollyer, Rosendorff, and Vreeland 2011)? Do election boycotts help or hinder the opposition's chances of being in power (Lindberg 2006a) or help to bring about political reform (Beaulieu 2006)? Does linkage to the West improve an opposition party's prospects (Levitsky and Way 2005)? What factors, such as opposition unity, can help break the dominance of an incumbent (Howard and Roessler 2006)? How does political competition in early elections influence democratic stability (Wright 2008)? Which institutional factors, such as elections, are "pathways from authoritarianism" (Hadenius and Teorell 2007) or "portents of pluralism" (Brownlee 2009)?

In the sections that follow, we propose a new measure of the potential for electoral competition, present alternative methods used to infer the existence of competition, compare these measures to our proposal, and provide an empirical comparison of alternative methods used to select the appropriate universe of cases, showing why a clear and direct measure of electoral competition is useful and substantively important.

\footnotetext{
${ }^{1}$ Replication Data are available at Susan D. Hyde and Nikolay Marinov, "Replication data for: Which Elections Can be Lost?," IQSS Dataverse Network, V1, available at http://hdl.handle.net/1902.1/16678. Planned updates of the data go through elections held in 2010, and further updates are tentatively planned. The data and all updates will be posted at http://hyde.research.yale.edu/nelda. and at http://www.nikolaymarinov.com/.
} 


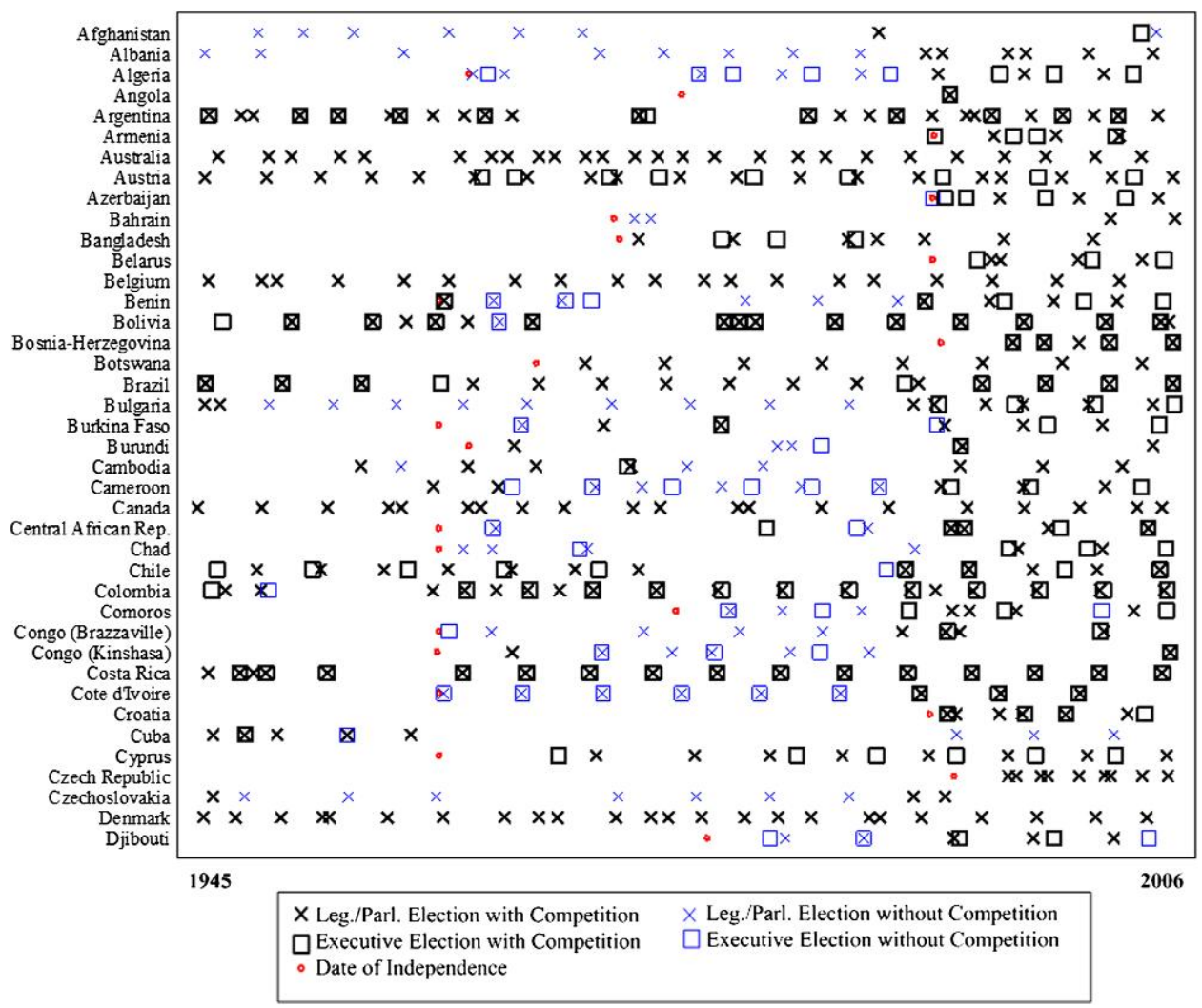

Fig. 1 Timeline of elections and competition 1945-2006.

\section{The National Elections Across Democracy and Autocracy Measure of Electoral Competition}

This project is motivated by two stylized facts. First, most governments in the world now hold elections, and some of these leaders have no intention of giving up power were they to lose. The group of countries that do not hold direct national elections continues to shrink and is currently less than a dozen. ${ }^{2}$ The practice of combining aspects of democratic and authoritarian rule is not new (Hermet, Rose, and Rouquie 1978 ) but, as Brownlee $(2009,515)$ summarizes, "in the 1990s rulers were fusing plebiscitarianism and authoritarianism at an astounding rate." Second, even leaders who hold rigged elections lose some of the time (even if they do not always give up power), indicating that elections can pose some threat even to those leaders who engage in serious election manipulation.

Which elections pose a threat to the incumbent leadership of a country and which are structured such that the incumbent cannot lose? It has proven difficult to distinguish between faux elections and contests that pose a possible threat to the government in power, particularly when some governments attempt to "reap the fruits of electoral legitimacy without running the risks of democratic uncertainty" (Schedler 2002). The underlying challenge for measurement was formulated in Giovanni Sartori's landmark 1976 study of party systems:

Since competition includes competitiveness as a potential outcome, competition is equal to, and can be defined as, potential competitiveness. Conversely, competitiveness presupposes competition (as a structure) and is something to be measured in outcome, on the basis of its effectiveness. Thus competitiveness is one of the properties or attributes of competition. (Sartori 1976, 218, emphasis in original) 


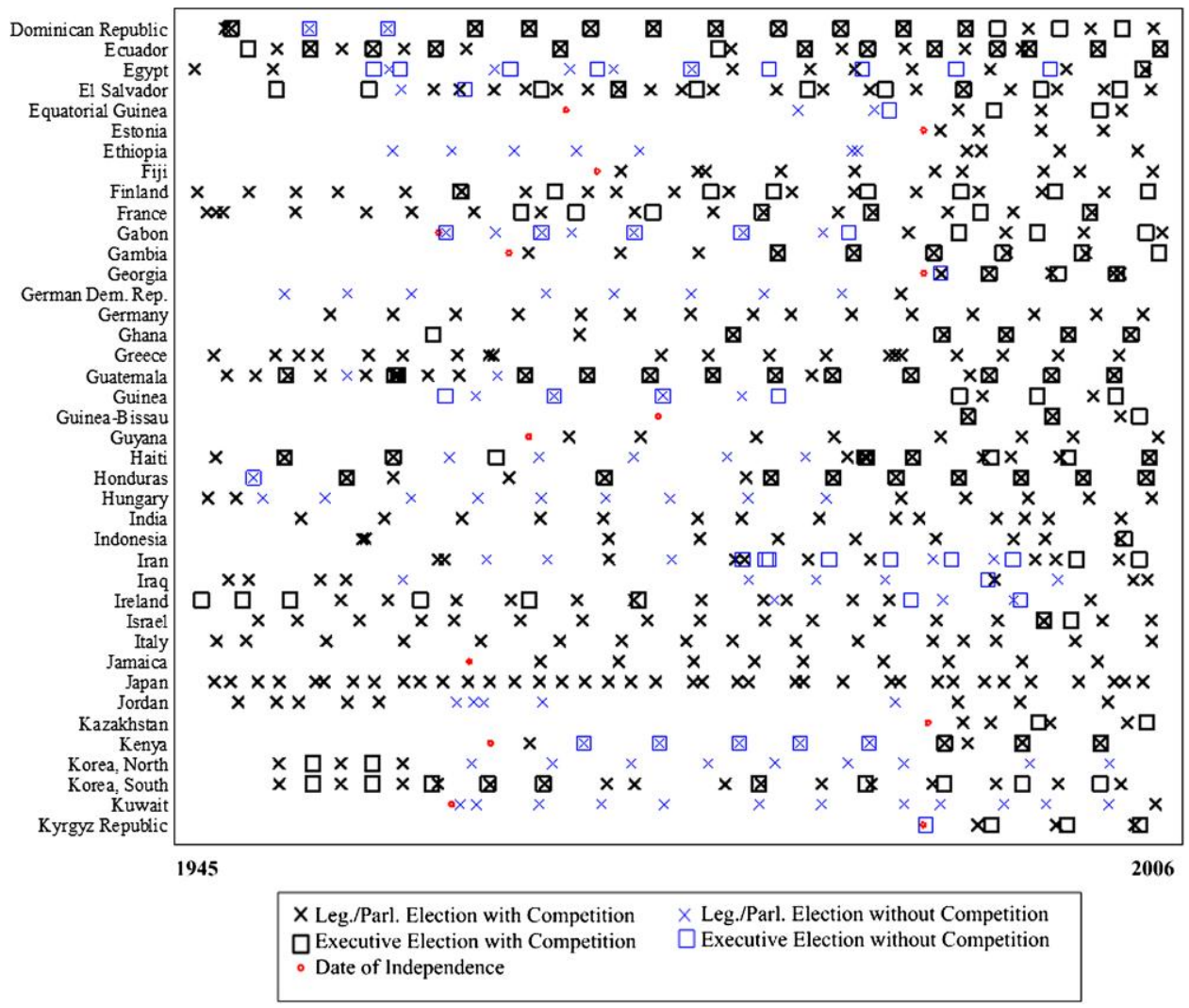

Fig. 2 Timeline of elections and competition 1945-2006.

In this formulation, the institution of contested elections can be thought of as a structure of the game and the electoral outcome as the realization of a random variable. Where the realization is at least in some doubt, competitiveness can exist. Where the outcome is certain, the structure prohibits competition and elections cannot be competitive.

So how can one distinguish between elections in which the outcome is certain and those in which some uncertainty exists? In a given election, we argue that competition is possible when opposition is allowed, multiple parties are legal, and more than one candidate is allowed on the ballot. If any of these criteria are violated, the election cannot be lost. Thus, the National Elections Across Democracy and Autocracy (NELDA) data measure the concept of competition as the joint product of these three factors, coded as binary answers to three questions for every election event: (1) was opposition allowed?, (2) was more than one party legal?, and (3) was there a choice of candidates on the ballot? These variables are labeled, respectively, as Nelda3, Nelda4, and Nelda 5 in the data. Table 1 presents pairwise correlations. If a national election meets all three conditions, we define the election as one in which competition is allowed. This group of elections represents the full universe of cases for many research questions. These variables may also be used separately or in other combinations when appropriate or combined with additional indicators relevant to specific research questions.

Table 1 Correlation between measures of competition

\begin{tabular}{lccc}
\hline & $\begin{array}{c}\text { Nelda3: } \\
\text { opposition? }\end{array}$ & $\begin{array}{c}\text { Nelda4: } \\
\text { >1 parties? }\end{array}$ & $\begin{array}{c}\text { Nelda5: } \\
\text { >1 candidates? }\end{array}$ \\
\hline Nelda3: opposition? & 1.0 & 1.0 & \\
Nelda4: $>$ 1 parties? & 0.8 & 0.6 & 1.0 \\
Nelda5: $>$ 1 candidates? & 0.7 & & \\
\hline
\end{tabular}




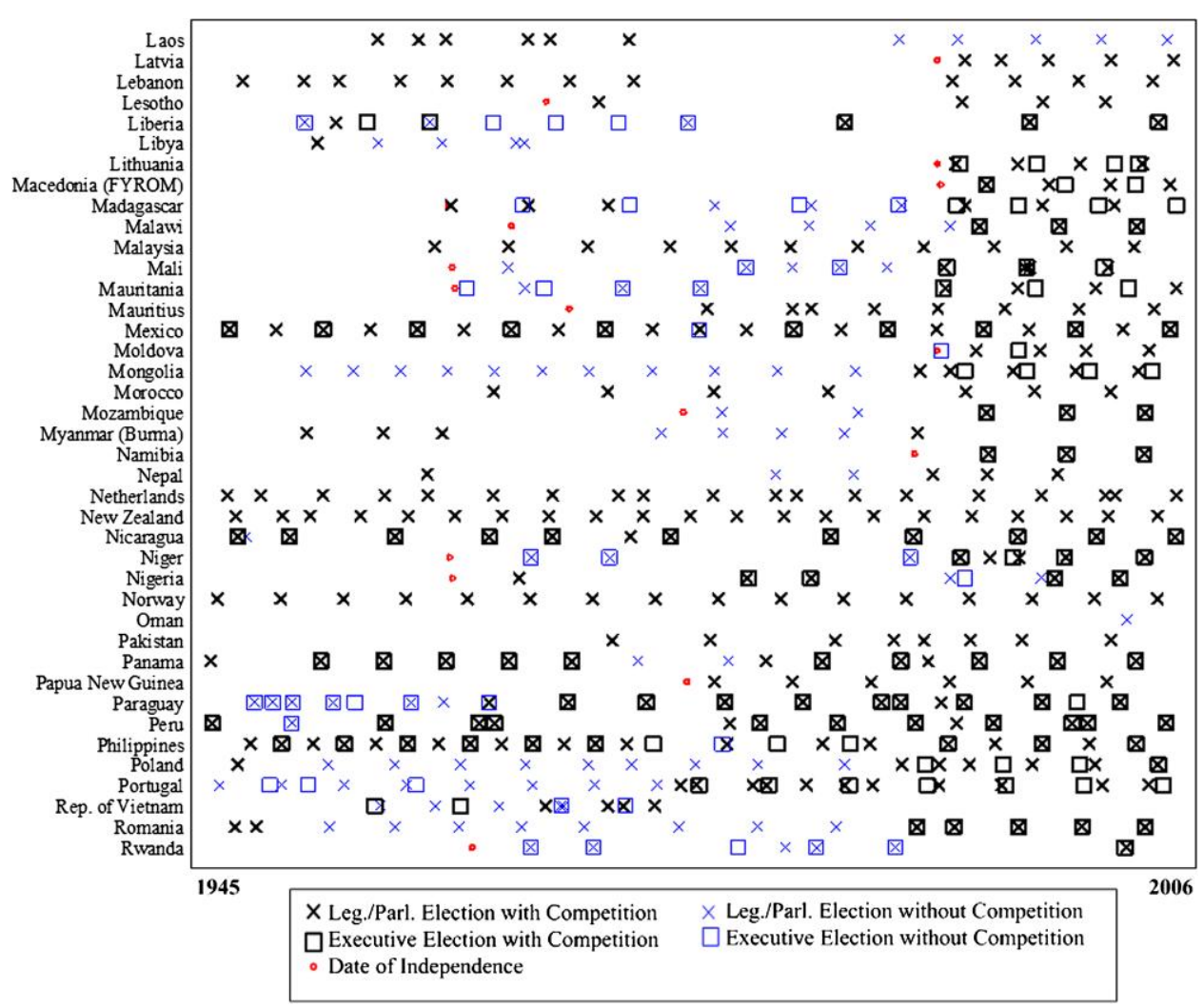

Fig. 3 Timeline of elections and competition 1945-2006.

A focus on which elections allow competition is similar to work on democracy by Przeworski et al. (2000). According to Przeworski et al. (2000), a democracy is characterized by political contestation defined by three features: (1) ex ante uncertainty, (2) ex post irreversibility, and (3) repeatability. Our proposed measure is not intended to measure broader categories of regime type and can be understood as an indicator of only ex ante uncertainty, which Przeworski et al. (2000) do not measure separately. Their distinction between uncertainty and unpredictability also applies here:

Uncertainty is not synonymous with unpredictability: The probability distribution of electoral chances is typically known. All that is necessary for outcomes to be uncertain is that it be possible for some incumbent party to lose. (Przeworski et al. 2000, 16-17).

We do not attempt to measure ex post irreversibility nor repeatability. A additional technical but sometimes important distinction is that our measure applies to individual election events rather than country years.

With this measure, we implicitly make several proposals. The first is simply that these three variables represent a minimalist measure of the potential for electoral competition, which we explain in detail below. ${ }^{3}$ Second, we argue that researchers engaging in cross-national research on the consequences of electoral competition should begin with the full set of elections allowing competition as the appropriate universe of cases. Idiosyncratic adjustments to the appropriate universe of cases or nonrandom sampling not only introduce bias but also make comparison of findings across researchers problematic.

Our first proposal is relatively straightforward: We measure directly what many scholars have referenced for decades. In terms of the second proposal, it may be that our definition is "too" minimalist,

${ }^{3}$ Some scholars prefer the term "competition" (Schumpeter 1942; Sartori 1976), whereas others prefer the term "contestation" (Dahl 1971; Przeworski et al. 2000). In this context, we consider them to be synonymous. 


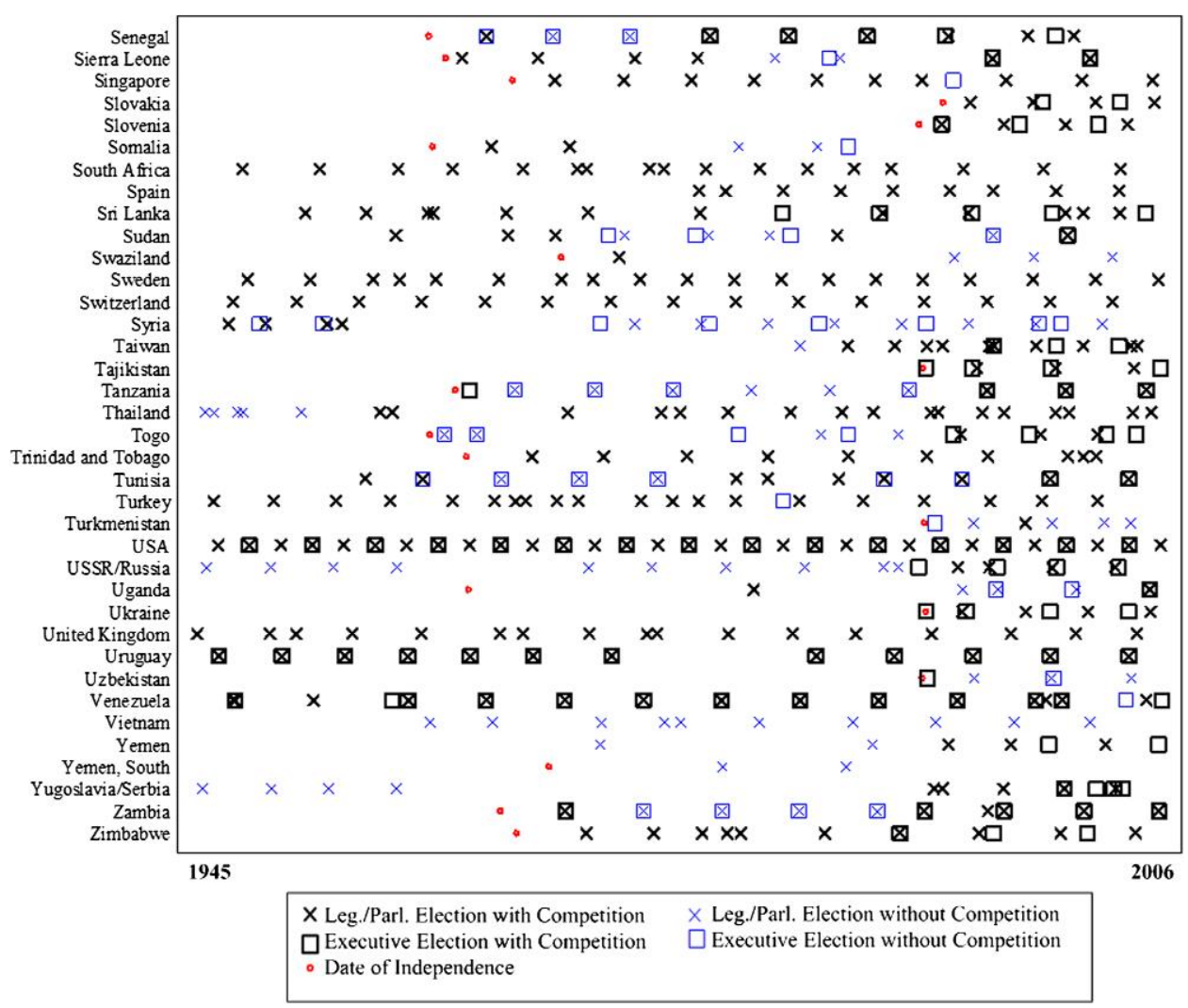

Fig. 4 Timeline of elections and competition 1945-2006.

and we claim that some elections could have been lost when in fact they could not. We address this second issue in greater detail when we compare the NELDA data to the available alternatives and argue that the minimalist approach is a useful starting point even for researchers who would prefer a more detailed measure. Future researchers can use the NELDA measure as a starting point from which to evaluate or add other criteria that may serve as better predictors of which elections have the potential for competition.

The NELDA data set includes information on more than 2600 election events in 157 countries. This represents all independent states with a population greater than 500,000 between 1945 and 2006, with statehood defined by Gleditsch and Ward (1999). All elections for national office are included. Referenda are generally excluded unless they are votes on the continued rule of a specific individual. In addition to the competition criteria, the data set includes information on more than 50 attributes of electoral events that are not discussed here, such as whether the incumbent contested the election, extended their term limit, or designated a chosen successor. In its most disaggregated form, NELDA codes executive and legislative elections separately, even if they occur on the same day, so that measures of competition can be separated by office and by election round.

Data were coded by a team of undergraduate and graduate research assistants who were each trained for several weeks on practice data, and research assistants (RAs) met with the principal investigators weekly during coding in order to discuss problematic cases. Sources used to code the data are diverse, including scholarly studies of specific countries, the elections data handbooks published by Oxford University Press (Nohlen, Krennerich, and Thibaut 1999; Nohlen, Grotz and Hartmann 2001; Nohlen 2005), historical news archives available through ProQuest and Lexis-Nexis, the Inter-Parliamentary Union's data and archives on parliamentary elections, and a number of other sources. RAs were trained to find multiple sources for information that was potentially controversial. Foreign language sources were used when appropriate and possible. The data include notes on special circumstances or clarifications for each question. 
For each of the three questions that measure competition, there were four possible responses: "yes," "no," "unclear," or "N/A." Among two coders, the intercoder reliability rates, with $25 \%$ of the data coded by two RAs, are $91 \%$ for Nelda3, $96 \%$ for Nelda4, and $96 \%$ for Nelda5. If the comparison is limited to cases in which both coders answered "yes" or "no," the corresponding rates of agreement are slightly higher.

Nelda3 indicates whether at least one opposition group existed to contest the election. Some countries have multiple government parties or no opposition. An opposition party or group is one that is not in the government and is not affiliated with the party in power. An example of a special case includes a number of elections in Iran in which opposition parties are technically allowed but all candidates must be approved by the Guardian Council, which has approved only a small fraction of applicants in the past. Even though opposition parties are restricted in this case, because some opposition is allowed, Nelda3 is coded as "yes."

The variable Nelda4 indicates whether multiple political parties were technically legal. The legalization of multiple parties does not necessarily mean the existence of a functioning opposition party, as there may be other nonlegal barriers to the development of an opposition party. This variable does not indicate whether any party is banned from participating in the election, but it does require that a party exists, is legal, and that the nongovernment party is an independent political entity. For example, in the 1947 election in Poland, the Communist Party allowed the Polish Peasant Party of Stanisław Mikołajczyk to campaign and run in the election. Despite murders and mass prosecutions of its activists, the Party managed to garner $10 \%$ of the (officially announced) popular vote (Staar 1958). ${ }^{4}$ Thus, according to our definition, the 1947 elections allow competition (Nelda3 and Nelda4 are "yes") and subsequent elections in Communist Poland do not (Nelda3 is "no" and Nelda4 is "yes"). Even though different parties were allowed to exist after 1947, they were controlled by the Communists.

Thus, Nelda 3 and Nelda 4 correlate highly but capture somewhat different means of eliminating competition. When opposition is allowed but multiple political parties are not legal, the government has officially banned all parties but allows some opposition candidates to exist and even campaign, usually as independents. When opposition is not allowed but multiple parties are legal, the legal parties are typically only government organized "opposition" parties. The combined use of these variables helps to distinguish between real opposition and regime-organized fronts. To illustrate, in the 2000 presidential election in Uzbekistan, President Karimov faced one supposed opposition opponent, but the opponent did not campaign, was from the governing party, and, when asked, even admitted to supporting and voting for the incumbent president. In this election, Nelda3 is coded as "no."

Finally, Nelda5 indicates whether voters were allowed to make a choice between candidates on the ballot, which is possible when the number of candidates competing for a slot exceeds the number of slots to be filled. A country may allow opposition to exist, make multiple parties legal, but eliminate any choice on the ballot for the office or offices in question, thus eliminating the possibility of competition.

As shown in Table 1, these three variables correlate highly but not perfectly, indicating that in practice, governments use different institutional strategies to eliminate the possibility of competition. There are nearly 2400 first-round elections in the NELDA data. Of these, more than 500 fail the competition criteria, meaning that "yes" was not the answer to Nelda3, Nelda4, or Nelda5. Which of the three NELDA variables causes cases to miss the competition criteria? There are about 200 elections that meet none of the competition criteria (37\%). Nelda3 alone leads about $6 \%$ of elections to fail the competition criteria, Nelda 4 alone causes about $15 \%$ to drop out, and Nelda 5 causes $7 \%$ to fail the competition criteria. The remaining elections fail two of the three criteria.

Theoretically, the NELDA competition criteria are intended to measure a widely referenced concept of when an election can be meaningful, and the measure is grounded in a party-based concept of electoral contestation (Sartori 1976; Przeworski et al. 2000; Greene 2007). As Przeworski et al. argue, "contestation occurs where there exists an opposition that has some chance of winning office as a consequence of elections" (Przeworski et al. 2000, 16).

\footnotetext{
${ }^{4}$ Even this was perceived as a threat to Stalin, and he ordered that the party be dissolved following the 1947 election.
} 
Are all three criteria necessary? The short answer is yes, with a few minor exceptions. Although the criteria are correlated, there are three types of unlosable elections that are separately captured by each variable. First, if opposition is not allowed but more than one party is legal and there is a choice of candidates on the ballot, an election cannot be lost by the incumbent because any victory in such an election will mostly likely be for a regime-installed puppet. ${ }^{5}$

If only one party is legal but opposition to the regime is allowed and there is a choice of candidates on the ballot, the election is conceptually unlosable because no opposition party can assume power, even if an anti-regime "independent" group of candidates manage to win a few extra seats. In the post-WWII era, competition is theorized as partisan, and the requirement for multiple political parties is more theoretical than practical. ${ }^{6}$

Finally, if opposition is allowed, multiple parties are legal, but there is not a choice of candidates on the ballot, then the election cannot be lost on a purely practical basis. If there is no choice of candidates for the office(s) in question, there can be no loser. The one glaring exception to this rule in our data is the 1988 Chilean referenda on the continued rule of Augusto Pinochet. Even though he ran against himself, he still managed to lose to the "no" vote. It is also technically possible for a write-in candidate to win a single-candidate election, but we do not know any examples of this occurring (to date) in a national election.

Nevertheless, our measure does not prohibit scholars from changing the assumption that all three variables are necessary for competition to be possible. One could easily use only one or two of the three variables as the threshold for competition. Such a definition would be even more minimalist than the measure we propose, and in our view, it would be more controversial.

Figures 1-4 illustrate the global spread of elections and competition over time, between 1945 and 2006. ${ }^{7}$ Squares $(\square)$ mark executive elections and "X"s mark legislative elections. Bold symbols indicate elections in which competition is possible. General elections (simultaneous presidential and legislative elections) are indicated when both symbols are overlayed. These figures are intended to illustrate general trends, and some borderline cases should still be debated. ${ }^{8}$

\section{Existing Approaches to Which Elections Can Be Lost}

How is the NELDA data different from alternatives? In this section, we outline three methods used by scholars to infer appropriate samples for empirical studies of the causes and consequences of electoral competition. In practice, these methods are sometimes combined in idiosyncratic ways. As we argue below, all three are potentially problematic in ways that can be remedied by measuring the potential for competition directly.

The three rules are commonly used in a number of research agendas in international relations and comparative politics but are perhaps most explicitly discussed in the burgeoning research on elections "without democracy," including studies of hybrid regime types like electoral authoritarianism and competitive authoritarianism (Diamond 2002; Levitsky and Way 2002, 2010; Howard and Roessler 2006; Schedler 2006; Brownlee 2009). The use of these rules is also common in political economy and other area of international relations in which an important characteristic of a state is whether the government faces electoral accountability.

\footnotetext{
${ }^{5}$ By construction, opposition not allowed indicates that only regime-controlled candidates compete.

'If we were to extend the data prior to 1900 , we would need to account for nonpartisan elections that allowed competition (Przeworski et al. 2000, 20).

${ }^{7}$ To avoid overprinting, when an election includes more than one round, only the first is shown.

${ }^{8}$ For example, parliamentary elections in Singapore include a (sometimes significant) percentage of seats that were uncontested and in which the government party won many seats by default because no other party fielded a candidate in that district. Although competition is not possible for all seats in any legislative election in Singapore, we code it as meeting the competition criteria because competition is allowed in some parliamentary seats. Although unlikely, a strong showing by opposition parties would have been a significant gain for the opposition and a stinging rebuke of the incumbent regime. Another special case occurred in Colombia during the Frente Nacional. During this period (1958-1974), the number of seats in the legislature was allocated to each party before elections took place. The presidency alternated between the two parties on a regular electoral cycle. Because the elections were contested within parties and multiple parties existed, we chose to consider these elections as allowing competition, but it is a borderline case.
} 


\subsection{Rule 1: Outcome-Based Measures of Competition}

Perhaps the best known statement of what we refer to as the outcome-based rule of electoral competition comes from Diamond $(2002,29)$ : "In regimes where elections are largely an authoritarian façade, the ruling or dominant party wins almost all the seats: repeatedly over 95 percent in Singapore, about 80 percent in Egypt in 2000 and Mauritania in 2001, 89 percent in Tanzania in 2000, and repeatedly over 80 percent in Tunisia during the 1990s." Making a similar point and echoing Diamond, Levitsky and Way $(2002,55)$ write: "As a rule of thumb, regimes in which presidents are reelected with more than 70 percent of the vote can generally be considered noncompetitive." Sometimes, an outcome-based rule is not invoked alone but forms part of larger classification scheme of regime types: The Database of Political Institutions codes political systems in which multiple parties win legislative seats and the largest gets over 75\%. ${ }^{9}$ The general approach of using outcomes to infer the existence of institutional structures is also present in Przeworski et al. $(2000,27)$ who use the vote share of the winning party in their classification of democracies and dictatorships.

There are three problems with using an outcome-based rule to define the potential for competition. First, significant and arbitrary assumptions are required to specify the maximum vote share any incumbent can receive in a democratic election, as well as the lowest vote share an authoritarian incumbent will accept as the minimum threshold of winning. Any such threshold will be noisy and will aggregate different "types" of elections (and both democratic and autocratic incumbents) on either side of the threshold. ${ }^{10}$ There is no reason why a completely democratic leader could not win in an overwhelmingly victory nor why an authoritarian leader (who anticipated such a threshold) cannot falsify a victory of less than any given threshold in order to appear more democratic. In fact, there is evidence that some authoritarian leaders have falsified election results to ensure that their margin of victory is not "too high." Because popular leaders sometimes commit electoral fraud (Simpser 2005), popularity and fraud are indistinguishable in some cases.

Second, although it is likely that any outcome-based rule will exclude some regimes with higher levels of anti-opposition bias, such a rule of thumb opens the door to post hoc coding decisions. A regime that is, ex ante, viewed as one with the potential for electoral accountability may be coded as noncompetitive if the election happens to lead to an $80 \%$ victory for one party. The opposite is possible for the case of stunning opposition victories in which parties overcome severe bias against them.

However, the third and most serious issue is that if an outcome-based rule is used to determine the universe of elections included in a study, it is often a clear case of selecting on the dependent variable. This is a well-known problem and arises when scholars are studying the determinants of electoral competition based on the outcome of the election. ${ }^{11}$ Selecting on the dependent variable generates biased estimates of the parameters and unreliable inferences about the validity of the hypotheses. The following model illustrates this problem in relation to electoral competition.

\subsection{A Simple Model of Electoral Competition}

Many (if not all) elections are manipulated contests (Gandhi and Przeworski 2009), and the level of manipulation varies along a continuum. ${ }^{12}$ For simplicity, we focus on elections in which the incumbent leader (or incumbent political party) is running, the opposition is challenging the incumbent, and if the incumbent loses, the opposition assumes power. For every candidate or political party, there is some vote share that

\footnotetext{
${ }^{9}$ Magaloni $(2006,35)$ uses a $65 \%$ cutoff rule as part of a broader coding scheme to identify hegemonic systems.

${ }^{10}$ Diamond $(2002,32)$ implicitly recognizes that outcome-based measures will lead to this type of problem when discussing an example of hegemonic authoritarianism (regimes where elections pose no risk to the party in power): "[T]he hegemonic character of rule by Hun Sen's Cambodian People's Party (CPP) was not apparent in the bare majority of parliamentary seats it won in 1998, but it became more blatant in early 2002 when the CPP won control of about 99 percent of the 1,621 local communes with about 70 percent of the vote".

${ }^{11}$ As King, Keohane, and Verba note, "When observations are selected on the basis of a particular value of the dependent variable, nothing whatsoever can be learned about the causes of the dependent variable without taking into account other instances when the dependent variable takes on other values" (King, Keohane, and Verba 1994, 129)."

${ }^{12}$ In this use of manipulation, we include legal tactics such as gerrymandering, unequal access to resources, or other relatively benign methods of biasing an election.
} 
the incumbent party would receive if elections were entirely free and fair and voters were able to translate their preferences accurately into representation. Let $x$ be the share of the vote that the incumbent would receive in a manipulation-free election, where $0 \leqslant x \leqslant 1$. Let $\beta \in \mathbb{R} \geqslant 0$ measure the election's bias in favor of the incumbent. Assume that this bias influences the results of the election according to the following function:

$$
f(x)=x^{\frac{1}{1+\beta}} .
$$

Here $0 \leqslant x \leqslant 1$ is the vote share the incumbent would get if elections were free and fair and $\beta \in \mathbb{R}_{\geqslant 0}$ is a measure of the bias in favor of the incumbent. When $\beta=\beta_{0}=0$, the official vote share equals the free and fair election vote share, as it would in an ideal democracy. Larger values of $\beta\left(\beta_{2}>\beta_{1}>0\right)$ distort the playing field progressively more in favor of an incumbent victory. The true incumbent support $x$ is unobserved but may be imagined as an indicator of the incumbent's true support absent any bias. Voters and scholars observe only $f(x)$ and whether the incumbent wins or loses. The required number of votes necessary to win varies by electoral system and the type of election. Nevertheless, for illustrative purposes, we simplify the model of the electoral system such that the incumbent wins if and only if $f(x)>0.5$.

As Figure 5 illustrates, an outcome-based cutoff point for excluding "uncompetitive" elections, such as $80 \%$ of the vote, potentially includes or excludes elections conducted under different values of the the distortion parameter $\beta$, leading to a biased sample for a number of relevant research questions. For example, assume that a researcher wishes to test how the opposition's chance of winning elections is affected by government control of the media or some other form of election fraud or manipulation. On Figure 5, state-run media produces a level of manipulation defined as $\beta=\beta_{2}$. If the government does not control the media, the level of manipulation is represented as $\beta=\beta_{1}$. A test of the hypothesis that state-run media produces less competitive election results would evaluate whether $\beta_{2}>\beta_{1}$.

If Rule 1 were used to define the universe of cases for an empirical test of the null hypothesis that $\beta_{2} \leqslant \beta_{1}$, the researcher would systematically exclude many cases of high manipulation and poor opposition performance, thus (downward) biasing the test of the relationship between state-run media (or any other strategy) on the probability that the incumbent will lose the election. By virtue of the sample selection, the researcher may erroneously conclude that state-run media has little or no effect on opposition performance.

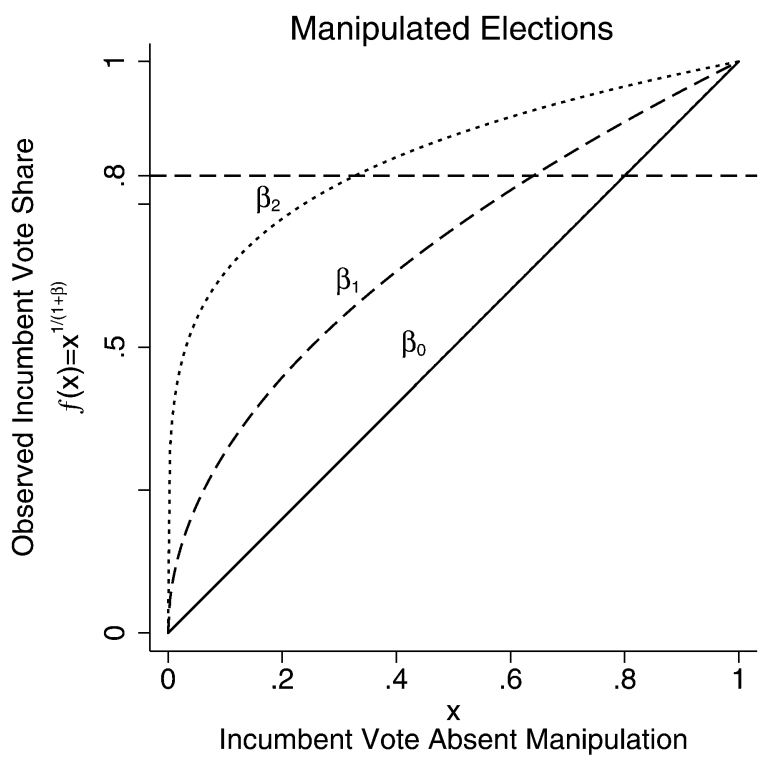

Fig. 5 Election outcomes with and without manipulation. 
In short, when attempting to estimate the effect of a particular incumbent or opposition strategy on the likelihood of a specific electoral outcome (such as a regime change or a democratic breakthrough), excluding that some observations based on their electoral outcomes is not an advisable strategy. ${ }^{13}$

\subsection{Rule 2: Competition Boundaries Defined by Regime Classification}

Political regimes are defined in the study of politics for many different reasons, and a comprehensive summary of the literature on regime type is beyond the scope of this project. Nevertheless, some researchers use regime-type boundaries as shorthand for which elections can be lost or select the universe of cases for a study based on regime type when the intended universe is the full set of countries that allow electoral competition. ${ }^{14}$ This may be because it was once the case that democracy was shorthand for multiparty elections, and authoritarianism was shorthand for a country that allowed no elections. The spread of elections to hybrid regimes should have done away with such shortcuts. Nevertheless, some scholars continue to argue that democracy is a valid shortcut for distinguishing among countries that allow any electoral competition and those that do not. On the other end of the regime-type spectrum, other scholars argue that hybrid regime types such as hegemonic authoritarian regimes are, by definition, regimes in which elections cannot be lost. One problem with this rule is that many definitions of electoral authoritarian or hegemonic authoritarian regimes rely in part on outcome-based rule of competition (Rule 1). Thus, regimes qualify as hegemonic where incumbents win by some (sufficiently large) margin and where a particular party or movement is in power for a long time.

If hybrid regimes types were reliably defined in a manner that did not rely on Rules 1 or 3, Rule 2 is not as problematic. However, coming up with a reliable measure of hegemonic authoritarianism that can be replicated across countries (and regions) and that does not rely on election outcomes (Rule 1) has proven extremely difficult, and there is not yet agreement on the full list of hegemonic authoritarian regimes. Comparative case studies have documented a number of cases of hegemonic party dominance in which regimes pursue a strategy in which elections cannot be lost. Mexico under the Partido Revolucionario Institucional is a well-known case of hegemonic party dominance, and Kazakhstan appears to be a hegemonic regime now. But debate continues over a number of other important cases. Particularly challenging for our purposes are regimes in which the opposition wins a surprising victory under conditions in which such an upset was previously thought to be "impossible." Because surprising election results are often a way in which change in a regime type is recognized, it is difficult to use regime type to define which elections could have been lost by the incumbent but were not. In other words, regime type is a trailing indicator of consequential elections, not a predictor of which elections have the potential to be consequential.

\subsection{Rule 3: Competition Defined by a More General Data set}

The third rule used by some scholars is to infer the universe of countries that allow potentially competitive elections from more general indices that are not intended to study electoral competition, such as Polity IV or Freedom House. Usually justifying the use of these data sets by stating that better data do not exist, scholars have used these data to identify the set of elections that are potentially competitive. ${ }^{15}$ The main challenge in using such aggregated measures is that they are at best noisy approximations of elections and competition.

This rule most often takes the form of an assumption that any election held when a country falls between a range of values on an index is an election with competition. For example, a minimum threshold on the Polity variable in the Polity IV data set is assumed to mean that electoral competition is impossible and that all other elections held in a country above that threshold allow competition. Yet, by rules hard wired into Polity, the rankings do not distinguish between countries based on characteristics associated

\footnotetext{
${ }^{13}$ Also problematic is the use of a "lagged" value of the electoral return to classify a regime or the state of electoral competition. Essentially, a lag may help alleviate the ex ante/ex post tension described above, but does not alleviate the issue of coding on the dependent variable, which comes with the attendant risk of biased hypothesis testing.

${ }^{14}$ This technique is particularly common in the field of International Political Economy.

${ }^{15}$ Studies that rely in part on this type of approach include Hegre (2001), Mansfield and Snyder (2002), Diamond (2002), Lindberg (2006b), Howard and Roessler (2006), Kenyon and Naoi (2010), and Keefer (2007).
} 
with specific elections. For example, Argentina under Peron earns the same Polity score as the USSR under Stalin (-9), Germany and Denmark in 1895 (with elected legislature but with an executive not responsible to it) score in the same "midrange" of values as do Sweden and The Netherlands in 1900 (with limited franchise but alternation of power between fairly elected leaders). ${ }^{16}$ The democratic elections in Greece 1974 occur during a period in which the country receives a Polity score of -7 , which is the same score received by many regimes holding one-party contests in the Middle East, and Koštunica's breakthrough against Milošević occurred when the country was coded as an inauspicious -6 . The same score is assigned to Armenia on the eve of its presidential elections in 1996 and to the solidly communist elections in 1980 Poland.

This issue cannot be resolved by turning to Polity's subcomponent scores (see Vreeland (2008) and Cheibub, Gandhi, and Vreeland (2010) on the problem of aggregation). The subcomponent variables $X R C O M P, X R O P E N$, and PARCOMP are the three components in Polity IV that appear to be the most theoretically relevant to electoral conditions. Yet they all have the same rankings for a number of cases that are not equivalent in terms of the possibility of electoral competition. Thus, by design, even though the Polity data set is one of the most widely used sources of data on variation in democratic and authoritarian political institutions, it does not draw a distinction between elections that allow competition and those that do not.

Other data sets such as the Database of Political Institutions (DPI) have also been used to study elections (Beck 2001; Freedom 2007). DPI includes variables about elected legislatures and executives, along with variables indicating the nature of competition. Although the DPI comes closer to measuring electoral competition with its indices of legislative and executive competitiveness (variables LIEC and EIEC), these indices rely on outcome-based indicators. In EIEC and LIEC, a country receives the most competitive score when it holds elections in which there are multiple candidates running for office and no candidate obtains more than $75 \%$ of the vote. Assuming that countries allow competition (or not) based on the DPI, data set is, therefore, problematic under Rule $1 .{ }^{17}$

\section{Comparing the NELDA Measure of Competition to the Alternatives}

We measure competition such that it can be applied across regime types and is determined separately from election outcomes (Sartori 1976). The criteria we propose are intended to be a conservative and minimalist measure of which elections could theoretically pose a threat to the incumbent government or ruling party. This is the appropriate set of elections for many research questions, as it is less likely to open the door to bias by selecting on the dependent variable. It is helpful to think about the types of error produced by each strategy in terms of either type I error (excluding elections than can be lost) or type II error (including elections that cannot be lost).

By design, our measure of competition is unlikely to commit type I error and leave out elections from the sample that can, in fact, be lost. Although there is no general theoretical reason to prefer type I errors over type II in statistical tests, the conversation is somewhat different in the context of data collection. First, we think it will be easier for other scholars to use a data set that clearly aims for one type of error over another, rather than committing both but not doing so overtly. Second, it is much easier for scholars using our data in the future to exclude cases that possess some other characteristic that makes an incumbent loss impossible than it is for future scholars to include elections that could be lost but were erroneously excluded. From a purely practical standpoint in using existing data sets, it is easier to exclude visible cases than to include previously excluded cases. Finally, as validation, there are no cases of elections that fail

\footnotetext{
${ }_{16}^{16}$ See insightful discussion in Bilinski (2010). Also see Kenyon and Naoi (2008) for evidence of measurement error in that data set. ${ }^{17}$ For example, among nondemocratic regimes, Brownlee (2009) defines regimes with an EIEC or a LIEC score of 5 or greater as electoral authoritarian and then defines the subtypes of hegemonic authoritarian regimes as having scores of 5 or 6 and competitive authoritarian regimes as nondemocracies that score a 7. Countries receiving a score of five have multiple parties that are legal but they did not win seats. Similarly, in examining the effects of electoral accountability, Keefer (2007) dichotomizes the EIEC scale such that a country is defined as allowing electoral competitiveness if its score is 6 or 7 . Additionally, the DPI binary measures of executive and legislative elections do not accurately indicate when elections took place. Many presidential elections are also coded as legislative elections, many presidential elections are coded as legislative elections, more than 100 legislative elections are missing, and the justification for these decisions is unclear.
} 
our competition criteria in which the incumbent (or a chosen successor) has run and lost an election (per Nelda24). Even if we have incorrectly excluded some elections that can be lost, all elections are available as observations in the data set, including those that fail our proposed competition criteria.

Type II error in the selection of cases is a greater risk but can be addressed. If competition is a necessary but not sufficient condition for the outcome of the election to be in some doubt, then our measure may include some elections than cannot really be lost. ${ }^{18}$ Our response to this concern is threefold: (1) recent research emphasizing the role of agency over structures suggests that the possibility of an incumbent loss is conceivable when competition is allowed, even under onerous conditions for the opposition such as massive electoral fraud or widespread use of political violence; (2) even if some elections that cannot be lost are included in the full universe of elections with competition, it is most likely that they will add only noise to the data; and (3) those who view the measure as too minimalist can add additional criteria to our conditions for competition or propose an alternative set of variables that are sufficient for competition.

If competition is allowed in a given election, and if human agency or election strategies are relevant, then a minimal and structural definition of electoral competition should be used to define the appropriate universe of cases. Once the opposition is allowed to compete, as Bunce and Wolchik's studies have demonstrated, they have the opportunity to marshal available resources in order to demand further changes from the government, and a number of stunning opposition victories have occurred throughout the world. ${ }^{19}$

For example, consider the 2000 elections in Côte d'Ivoire. The incumbent President Robert Guei attempted to steal the election by severely limiting competition but without entirely banning it in order to appear as though he was allowing multiparty elections. Among other tactics, Guei ensured that 14 of the 19 prospective presidential candidates, including those from the two largest political parties, were barred from running by the supreme court. These actions led the UN-coordinated election observer mission to withdraw from the country and to issue a strong condemnation of the elections. However, Guei's efforts were apparently not sufficient to guarantee electoral victory, and in a surprise outcome, one of the four remaining opposition candidates won the presidency with $59 \%$ of the vote. Because minimal competition was allowed, our measure defines this case as allowing competition where other rules would exclude cases like this or condition inclusion on the outcome of the election.

What if the NELDA measure of competition overestimates the power of agency or opposition strategy to overcome severe pro-incumbent bias? In this is the case, our method would include some elections that would return incumbent victory with $100 \%$ certainty. Such type II error is most likely to add noise to hypothesis testing. If we are missing an important variable in our competition criteria which is sufficient to make electoral outcomes certain, it is likely to matter if the independent variable in question (such as media manipulation) is systematically related to the potentially "missing" competition criteria. If the independent variable in question (such as state-control and manipulation of the media) is unrelated to the hypothetical variable that is missing from the competition criteria, scholars can still evaluate causal relationships of interest without necessarily introducing bias. Table 2 summarizes the comparison between the NELDA competition criterion and common alternatives.

Table 2 Comparing different approaches to which elections can be lost

\begin{tabular}{lllll}
\hline & $\begin{array}{l}\text { NELDA: } \\
\text { competition }\end{array}$ & $\begin{array}{l}\text { Rule 1: } \\
\text { outcome }\end{array}$ & $\begin{array}{l}\text { Rule 2: } \\
\text { regime }\end{array}$ & $\begin{array}{l}\text { Rule 3: } \\
\text { polity }\end{array}$ \\
\hline $\begin{array}{l}\text { Type I error: } \\
\text { exclude can be lost }\end{array}$ & No & Yes & Maybe & Yes \\
\hline $\begin{array}{l}\text { Type II error: } \\
\text { include cannot be lost }\end{array}$ & Yes & Yes & Maybe & Yes \\
\hline
\end{tabular}

\footnotetext{
${ }^{18}$ This topic is raised by both Sartori (1976) and Przeworski et al. (2000).

${ }^{19}$ Bunce and Wolchik $(2010,59)$ put it in this way: “... the problem is not just the opportunities for electoral change such regimes provide; it is also the tensions they generate between real and 'fake' democracy, with the result that, 'if leaders use the forms of democracy, publics come to expect the substance.' "We concede that, sometimes, an election that is won by the opposition will not be conceded by the incumbent. We do not deal with this important issue here, other than to say that such instances are rare historically and we assume that domestic players expect that a victory of the opposition translates into an expecation of holding power.
} 
How does the NELDA-defined measure of electoral competition compare to the three alternative rules used to define the electoral competition described above? By definition, the NELDA criteria avoid the problems with Rule 1 in which the outcome of the election is used to judge whether competition was possible. The three variables used to define competition are all known before an election takes place. Using outcomes to select which elections to include in a sample is bound to both generate noise in the sample selection (because cut-points are necessarily arbitrary) and generate systematic bias when testing hypotheses about the determinants of political change.

Rule 2 may generate valid tests about the determinants of competitiveness, provided that outcomes are not used in defining regime types. Depending on the exact purpose of the regime classification, it is possible that either type I or type II error will be present (e.g., with democratic regimes, type II error is likely minimal as elections should not be won with certainty in any democracy. If hegemonic regimes were used as part of a classification scheme, type II error is more likely). It is potentially more productive to use the NELDA data to better understand variation among regime types rather than using regime type to define which elections allow competition. Scholars can use NELDA to test assumptions about distinctions among regime types. Especially where the goal of the researcher is to understand regime change, it is particularly important to define elections apart from regime type, as elections are one potential explanation for and marker of regime change. Thus, rather than arguing that regime typologies are not useful in the study of elections, we argue that conceptual separation between electoral competition and regime types can advance the study of both.

The difference between NELDA and Rule 3 is straightforward. Put simply, other data sets are not measures of electoral competition: they code directly neither Sartori's basic concept of competition nor degrees of competitiveness. The difference introduced by measuring competition directly is best illustrated graphically. Figures 6 and 7 compare the NELDA data to two widely used data sets on political institutions and political rights: the Polity IV data set (Marshall and Jaggers 2007) and the Freedom House data on political rights and civil liberties (Freedom 2007). Figures 6 and 7 illustrate the number of elections that allow competition and the number of elections that do not allow competition, per the NELDA data, at each level of the three indices. They show clearly that there is no threshold on these indices that includes the full universe of cases in which electoral competition is possible.

Some other data sets in political science include information on elections, and we include a more detailed discussion of the differences between them and NELDA in an online appendix. For the most part, other data sets are motivated by the study of democracy or democratization and are therefore restricted to democratic or nearly democratic elections. One partial exception is the Institutions and Elections Project (IEP) by Regan and Clark (2007), which is comparable to NELDA in terms of coverage and attention to elections, although it starts in 1973. There are also some nontrivial differences in how competition is defined and measured in the two data sets. IEP codes whether political parties are banned but does so at the level of country year, whereas NELDA does so at the level of the election round (and can be collapsed

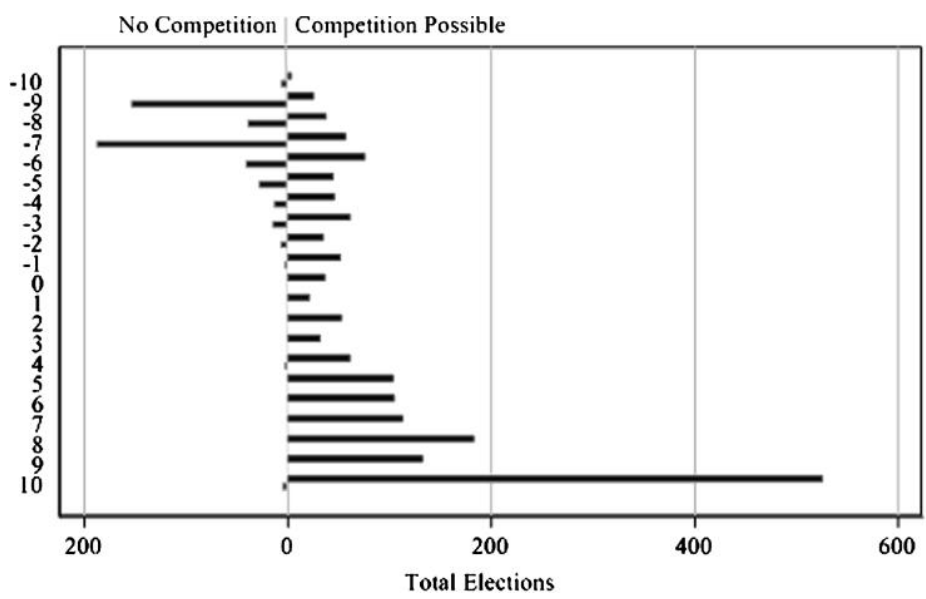

Fig. 6 Electoral competition by Polity IV index. 
(a) No Competition Competition Possible

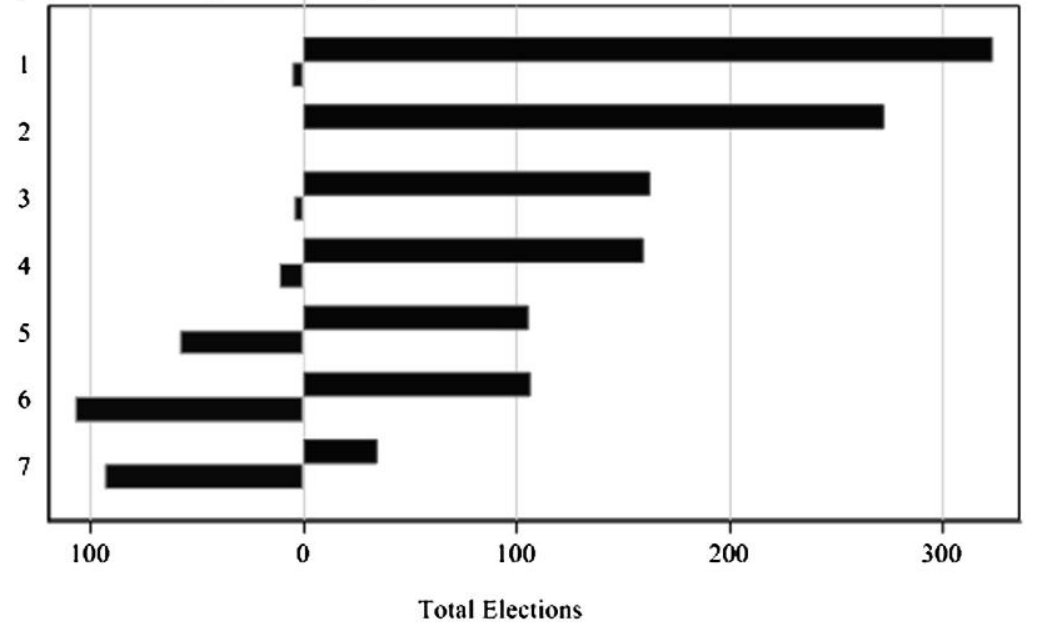

(b) No Competition Competition Possible

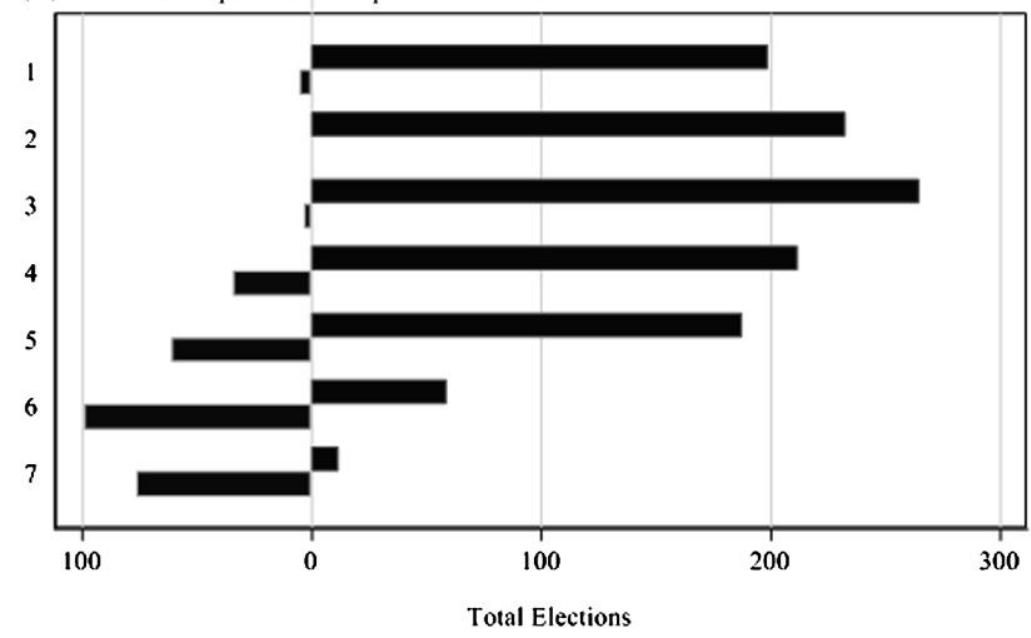

Fig. 7 Electoral competition by Freedom House indices. (a) Electoral competition by Political Rights index. (b) Electoral competition by Civil Liberties index.

into country-year data). The other competition criteria, such as whether there were multiple candidates on the ballot, do not appear to be available through IEP. That said, there are a number of variables of significant interest in the data by Regan and Clark (2007) and its attention to individual elections should make the two data sets complementary resources.

As mentioned earlier, the DPI data set does contain some variables that measure electoral competition (Beck 2001). However, our analysis suggests that they are not accurate measures of the potential for electoral competition. Of all elections that were either a gain for the opposition or a loss for the incumbent (both ex post measures of elections that must have allowed competition), DPI identifies more than $20 \%$ as noncompetitive. We have not yet uncovered why this discrepancy exists but have checked our codings against DPI's measures of elections and competition and have confirmed that (at least minimal) opposition did exist in many cases that are not counted as elections in DPI.

Of course, our data are also likely to contain errors, although our intercoder reliability tests indicate high levels of agreement. Because we measure the concept of electoral competition directly and seek to quantify errors while coding all elections between 1945 and 2006, we believe that our data are a preferable measure of competition in elections and the best available starting point to test hypotheses relating to the causes and consequences of electoral competition. 


\section{Illustrating the Importance of Sample Selection}

One area where the NELDA data should be particularly useful is in understanding what other factors influence how competitive election outcomes are likely to be. For such questions, the NELDA competition measure should be used to define the relevant universe of cases. In this section, we illustrate how sample selection matters, focusing on the problem of biased inferences and the risk of selecting cases on the dependent variable. Our simple illustration shows how media freedom influences election outcomes. We show that the estimates of how media freedom influences the probability of an incumbent party loss change significantly based on sample selection and that alternative methods of sample selection underestimate how media manipulation decreases the probability of an incumbent party loss.

\subsection{Sample Selection and Inferences About Media Freedom and Electoral Competitiveness}

Theoretically, a manipulated media hampers the ability of opposition parties to compete in elections and should make incumbent loss less likely. How should one define the relevant sample of elections on which to test hypothesis about limited media freedoms on whether incumbents lose elections? As we have argued, it would be a mistake to exclude cases based on the outcome of the election, and more general indices of political institutions or categories of regime type have the potential to produce similar problems.

Following the three alternative rules defined above, we specify four different methods of drawing the relevant sample-NELDA competition, margin of victory (Rule 1), regime type (Rule 2), and Polity/ Freedom House (Rule 3). We keep the example as simple as possible to maintain focus on the sampling issue. ${ }^{20}$

\subsubsection{Dependent Variable}

For our measure of competitiveness (as an outcome of the election), we examine whether the incumbent's party lost the election. This information is available as a binary indicator through Nelda24: Did the incumbent's party lose? If the incumbent or ruling party lost the election, then a "yes" is coded ${ }^{21}$ This is one plausible measure of competitiveness, as elections where the incumbent party is more likely to lose are more competitive, all else equal.

\subsubsection{Independent Variables}

For our independent variable of interest, we focus on manipulation of the media and its inverse, media freedom. We use two measures of media bias: one from NELDA and one from Freedom House.

Nelda16 measures the existence of pro-government media bias. The variable is a binary indicator that answers the question: "In the run-up to the election, were there allegations of media bias in favor of the incumbent?" If there were reports by either domestic or outside actors of media bias in favor of the incumbent or ruling party, it is coded as a "yes." In cases where the media is totally controlled by the government, the answer is "yes." It is possible that the answer is "no" even if the political system is tightly controlled or other forms of manipulation are used. This variable emphasizes perceptions among foreign and domestic actors about the existence of pro-government media bias.

A second measure is the Freedom House Freedom of the Press index, available for a large cross-section of countries for 1980-2006 and intended to capture the existence of free media. The score ranges from 0 to 100 , with scores from 0 to 30 regarded as free media; 31 to 60 partly free media, and 61 to 100 as not free. We have lagged this measure and subtracted it from 100 so that the metric is subject to a more natural interpretation: 0 -no media freedom and 100 - complete media freedom. The two measures tap related concepts. The less free the media is on the FH score, the more likely it is that this generates pro-government bias.

\footnotetext{
${ }^{20}$ We have also run similar analyses on other research questions, such as how opposition unity influences the probability of a "liberalizing electoral outcome," which is excluded due to space constraints. However, this comparison shows that the results from a prominent study on the subject are very sensitive to sample selection.

${ }^{21}$ Full documentation from the NELDA Web site, http://hyde.research.yale.edu/nelda.
} 


\subsubsection{Sample Selection}

Model (1) uses the competition criterion from NELDA to define the relevant universe of countries on which to evaluate the relationship between media manipulation and incumbent loss. Model (2) limits attention to elections in countries where the largest party holds less than a 0.75 share of the parliamentary or legislative seats. ${ }^{22}$ This is an example of using an electoral outcome to draw the relevant universe of cases. The data are available for 1974-2006 for a large set of countries. Model (3) uses Polity in combination with Freedom House (per common procedure) to include only elections scoring above -5 on the Polity 2 composite variable and under 6 on the political rights index (ruling out unfree rankings). This kind of combination has been used to identify the set of at least nominally competitive elections. ${ }^{23}$ Finally, in Model (4), we use the dictatorship and democracy dataset to select the subset of elections with competition that occur in procedural democracies. ${ }^{24}$ This is an example of using regime categories to specify the relevant universe of cases, and findings only apply to elections in procedural democracies. More subtly, because the way democracy is defined in that data relies at least partly on outcomes (elections lost, succession in power, and vote share), ${ }^{25}$ conditioning on regime type should generate similar results to excluding elections with large seat shares of the winning party.

\subsubsection{Comparing Inferences Across Samples}

Tables 3 and 4 show parameter estimates for the two independent variables of interest-pro-government media and press freedom - on the likelihood of incumbent party loss at the polls. To keep the samples in each table as comparable as possible, each sample is drawn from observations for which the covariates for all four models are available. Thus, even though Model (1) does not condition on seat share of the largest party, that sample and the samples in Models (3) and (4) are drawn for cases in which that covariate is non-missing. ${ }^{26}$ The number of elections in each model varies from over 1000 observations to about half of that (for the democracy subsample). Because the scales are different for the two dependent variables, the signs of the estimates should be opposite: negative in Table 3 (pro-government media makes incumbent party loss less likely) and positive in Table 4 (free media makes loss more likely).

Comparing across the models, the two tables show similar patterns: the estimated impact of the coefficient of interest for the full competition sample (Model 1) is greater than the impact when conditioning on seat share, Polity/Freedom House, and procedural democracy. Findings are similar across both measures of media bias.

Looking at Table 4, the impact of media freedom on incumbent party loss declines from Model (1) to Model (2), where the largest party holds less than 0.75 share of the elected seats. This is in line with the

Table 3 Sample selection and inferences on the importance of media freedoms for competitiveness (dependent variable is indicator of whether incumbent party lost)

\begin{tabular}{lcccc}
\hline & \multicolumn{3}{c}{ NELDA and three alternative sample selection rules } \\
\cline { 2 - 5 } & $(1)$ & $(2)$ & $(3)$ & $(4)$ \\
& $N E L D A$ & Seats $<.75$ & $6>$ FH/Pol $>-5$ & Democracy \\
Pro-government media & $-0.804(0.171)$ & $-0.631(0.191)$ & $-0.414(0.215)$ & $-0.094(0.271)$ \\
Constant & $-0.485(0.064)$ & $-0.370(0.068)$ & $-0.401(0.071)$ & $-0.232(0.084)$ \\
Log-likelihood & -805.05 & -703.88 & -632.67 & -434.83 \\
& $n=1262$ & $n=1063$ & $n=949$ & $n=634$ \\
\hline
\end{tabular}

Note. $\mathrm{SE}=$ standard error.

\footnotetext{
${ }^{22}$ The source of the data is the Quality of Governance dataset, which compiles existing sources (Teorell, Holmberg, and Rothstein, 2008). These elections are a subset of the contests allowing competition per NELDA.

${ }^{23}$ See Howard and Roessler (2006) for an example.

${ }^{24} \mathrm{See}$ Cheibub, Gandhi, and Vreeland (2010) on the data.

${ }^{25}$ See Przeworski et al. $(2000,1-51)$ for more on the specific rules.

${ }^{26}$ The idea is that any differences should be driven not by the availability of covariates (which may be systematically available or not for earlier historical periods or certain countries) but by the substantive sample selection rule alone.
} 
Table 4 Sample selection and inferences on the importance of media freedoms for competitiveness (dependent variable is indicator of whether incumbent party lost)

\begin{tabular}{|c|c|c|c|c|}
\hline & \multicolumn{4}{|c|}{ NELDA and Three Alternative Sample Selection Rules } \\
\hline & (1) & (2) & (3) & (4) \\
\hline & NELDA & Seats $<.75$ & $6>$ FH/Pol $>-5$ & Democracy \\
\hline & $\beta_{(S E)}$ & $\beta_{(S E)}$ & & \\
\hline $\begin{array}{l}\text { Press freedor } \\
\text { Constant }\end{array}$ & $0.018(0.002)$ & $0.014(0.003)$ & $0.013(0.004)$ & $-0.006(0.005)$ \\
\hline Const: & $1.654(0.185)$ & $-1.278(0.208)$ & $-1.300(0.272)$ & $0.229(0.373)$ \\
\hline Log-likelihood & $\begin{array}{c}-737.80 \\
n=1160\end{array}$ & $\begin{array}{c}-647.02 \\
n=976\end{array}$ & $\begin{array}{c}-579.51 \\
n=870\end{array}$ & $\begin{array}{c}-387.68 \\
n=563\end{array}$ \\
\hline
\end{tabular}

Note. $\mathrm{SE}=$ standard error.

model presented in Figure 5. If unfree media is a form of advantage to the incumbent ( $\beta$ in that figure), excluding elections that yield less competitive results should attenuate the estimate on the parameter of interest. Moving to Model (3), with the sample based on a combined measure of Polity/Freedom House, the size of the effect of media bias on incumbent victory decreases further. In Model (4), which restricts attention to procedural democracies, the estimated effect of media manipulation declines so much that it is difficult to distinguish from zero. The sample selection in Model 4 systematically rules out less competitive elections. Thus, the non-finding can be thought of as a form of sampling-induced bias.

Model 4 is not intended to question the validity of the procedural definition of democracy. Rather, our point is that if the goal of the researcher is to estimate the influence of a particular factor on degrees of electoral competitiveness, the researcher should weigh carefully the advantages and disadvantages of using regime type to restrict the sample. Most regime typologies that we are aware of (democracy, electoral authoritarianism, hegemonic authoritarianism, and so on) rely at least in part on electoral outcomes and so truncate the sample by competitiveness. In general, this has sometimes large implications for the estimated parameters of interest.

To further illustrate differences that can result from sample selection, Figure 8 shows predicted probabilities from the coefficient estimates in Models 1, 2, and 4 from Table $4 .{ }^{27}$ If unfree media (press freedom $=25)$ is a strategy used by incumbent parties stay in power, moving from free $(=75)$ to unfree media should increase the chances of an incumbent win. The figure shows how modifying the sample depresses the estimated effectiveness of this strategy. At a minimum, the researcher may underestimate the effect of biasing strategies and at the extreme may fail to find support for a hypothesis that, in fact, holds. The opposite is also possible for research questions in which less competitive elections are correlated with electoral strategy that is only likely to work at higher levels of democracy.

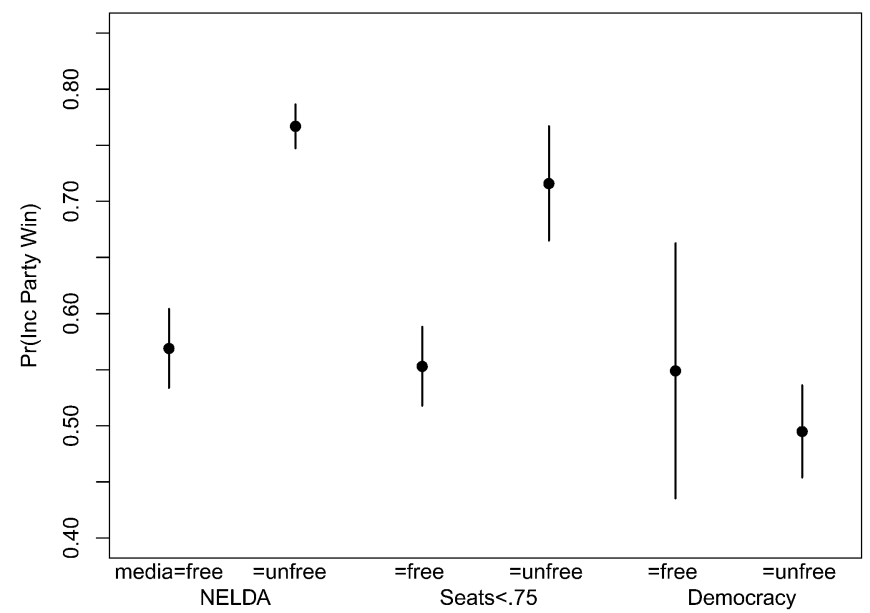

Fig. 8 Media freedom and incumbent party win.

${ }^{27}$ Predicted probabilities obtained with Clarify (King, Tomz, and Wittenberg, 2000). 


\section{Conclusions}

The contribution of this article is best illustrated by five related observations: First, for scholars evaluating the causes and consequences of electoral competition, outcome-based measures of electoral competition, by excluding elections in which the opposition can compete but did not perform sufficiently well, may introduce biased estimates in research on a wide-ranging set of questions. Second, broader measures of regime type or indices of political institutions do not identify the appropriate universe of cases on which propositions about how elections turn out should be tested. Third, no existing public data set has comparable scope of coverage of elections as unique and identifiable events. Fourth, relative to existing data sets on elections, the data are more flexible outside of the country-year format and can be easily transformed into the structure that is most appropriate to a specific research question. Finally, the list of election events makes adding additional election-specific variables relatively straightforward, a feature that we hope will facilitate further research and collaboration. This final point is simple but may arguably prove a lasting contribution of the project.

As elections have spread across regime types, attention to measurement of election-specific indicators of competition is a necessary step in understanding when and how elections matter, as well as evaluating the relationship between the structure of political institutions and strategies used by political actors to seek or maintain power.

\section{Funding}

We thank the MacMillan Center for International and Area Studies, the Institution for Social and Policy Studies, and the Jackson Institute at Yale University for generous support of this project. The authors declare no conflict of interest from receiving this funding.

\section{References}

Beaulieu, Emily. 2006. Protesting the contest: Election boycotts around the world, 1990-2002. PhD diss., Department of Political Science, University of California, San Diego.

Beck, Thorsten. 2001. New tools in comparative political economy: The database of political institutions. World Bank Economic Review 15:165-76.

Bilinski, Adam. 2010. Measuring basic characteristics of political regimes. Paper presented at the annual meeting of the Midwest Political Science Association, Chicago, IL, April 22-25.

Block, Steven A., Karen E. Ferree, and Smita Singh. 2003. Multiparty competition, founding elections and political business cycles in Africa. Journal of African Economics 12:444-68.

Brownlee, Jason. 2009. Portents of pluralism: How hybrid regimes affect democratic transitions. American Journal of Political Science 53:515-32.

Bunce, Valerie, and Sharon Wolchik. 2010. Defeating dictators: electoral change and stability in competitive authoritarian regimes. World Politics 62:43-86.

Cheibub, José, Jennifer Gandhi, and James Vreeland. 2010. Democracy and dictatorship revisited. Public Choice 143:67-101.

Dahl, Robert A. 1971. Polyarchy: Participation and opposition. New Haven, CT: Yale.

Diamond, Larry. 2002. Thinking about hybrid regimes. Journal of Democracy 13:21-35.

Freedom House. 2007. Freedom in the world country ratings, 1972-73 through 2007. http://freedomhouse.org/research/freeworld/ FHSCORES.xls.

Gandhi, Jennifer, and Adam Przeworski. 2009. Holding onto power by any means? The origins of competitive elections. Mimeo, Emory University, Atlanta.

Gleditsch, Kristian S., and Michael D. Ward. 1999. A revised list of independent states since the congress of vienna. International Interactions 25:393-413.

Greene, Kenneth. 2007. Voting for autocracy: Hegemonic party survival and its demise in Mexico. New York: Cambridge University Press.

Hadenius, Axel, and Jan Teorell. 2007. Pathways from authoritarianism. Journal of Democracy 18:143-57.

Hegre, Håvard. 2001. Toward a democratic civil peace? Democracy, political change, and civil war, 1816-1992. American Political Science Review 95:33-48.

Hermet, Guy, Richard Rose, and Alain Rouquie. 1978. Elections without choice. London: Macmillan.

Herrera, Yoshiko M., and Devesh Kapur. 2007. Improving data quality: actors, incentives, and capabilities. Political Analysis 15: 365-86.

Hollyer, James R., Peter Rosendorff, and James Raymond Vreeland. Forthcoming 2011. Democracy and transparency. Journal of Politics. 
Howard, Marc, and Philip Roessler. 2006. Liberalizing electoral outcomes in competitive authoritarian regimes. American Journal of Political Science 50:365-81.

Hyde, Susan D., and Nikolay Marniov. 2011. Replication data for: Which elections can be lost? ISQ Dataverse Network (Distributor), V1, Available at http://hdl.handle.net/1902.1/16678.

Jensen, Nathan M. 2003. Democratic governance and multinational corporations: Political regimes and inflows of foreign direct investment. International Organization 57:587-616.

Keefer, Philip. 2007. Elections, special interests, and financial crisis. International Organization 61:607-41.

Kenyon, Thomas, and Megumi Naoi. 2008. Democracy as a latent variable. American Journal of Political Science 52:201-17.

- 2010. Policy uncertainty in hybrid regimes: Evidence from firm-level surveys. Comparative Political Studies 43:486-510.

King, Gary, Michael Tomz, and Jason Wittenberg. 2000. Making the most of statistical analyses: Improving interpretation and presentation. American Journal of Political Science 44:347-61.

King, Gary, Robert O. Keohane, and Sidney Verba. 1994. Designing social inquiry: Scientific inference in qualitative research. Princeton, NJ: Princeton University Press.

Levitsky, Steven, and Lucan A. Way. 2002. The rise of competitive authoritarianism. Journal of Democracy 13:51-65.

- 2005. Ties that bind? Leverage, linkage, and democratization in the post Cold War World. International Studies Review 7:519-24.

. 2010. Competitive authoritarianism: International linkage, organizational power, and the fate of hybrid regimes. New York: Cambridge University Press.

Lindberg, Staffan. 2006a. Democracy and elections in Africa. Baltimore, MD: Johns Hopkins University Press.

Lindberg, Staffan. 2006b. Tragic protest: Why do opposition parties boycott elections? In Electoral authoritarianism: The dynamics of unfree competition, ed. Andreas Schedler, 149-63. Boulder, CO: Lynne Rienner.

Magaloni, Beatriz. 2006. Voting for autocracy: Hegemonic party survival and its demise in Mexico. New York: Cambridge.

Mansfield, Edward, and Jack Snyder. 2002. Democratic transitions, institutional strength, and war. International Organization 56:297-337.

Marshall, Monty, and Keith Jaggers. 2007. Polity IV project. Integrated Network for Societal Conflict Research (INSCR) Program. Center for International Development and Conflict Management (CIDCM), University of Maryland, College Park. http://www. cidcm.umd.edu/inscr/polity.

Munck, Gerardo, and Jay Verkuilen. 2002. Conceptualizing and measuring democracy: Evaluating alternative indices. Comparative Political Studies 35:5-34.

Nohlen, Dieter. 2005. Elections in the Americas: A data handbook. Oxford: Oxford University Press.

Nohlen, Dieter, Florian Grotz, and Christof Hartmann. 2001. Elections in Asia and the Pacific: A data handbook. Oxford: Oxford University Press.

Nohlen, Dieter, Michael Krennerich, and Bernhard Thibaut. 1999. Elections in Africa: A data handbook. New York: Oxford University Press.

Przeworski, Adam, Michael Alvarez, Jose Cheibub, and Fernando Limongi. 2000. Democracy and development: Political institutions and well-being in the World, 1950-1990. New York: Cambridge University Press.

Regan, Patrick, and Dave Clark. 2007. The institutions and elections project. Binghampton: State University of New York. http://www 2.binghamton.edu/political-science/institutions-and-elections-project.html.

Sartori, Giovanni. 1976. Parties and party systems: A framework for analysis. New York: Cambridge.

Schedler, Andreas. 2002. Elections without democracy: The menu of manipulation. Journal of Democracy 13:36-50.

Schedler, Andreas. 2006. Electoral authoritarianism: The dynamics of unfree competition. Boulder, CO: Lynne Rienner.

Schumpeter, Joseph A. 1942. Capitalism, socialism and democracy. New York: Harper \& Brothers.

Simpser, Alberto. 2005. More than Winning: The Strategic Logic of Electoral Manipulation. Book Manuscript, Chicago University.

Staar, Richard. 1958. Elections in Communist Poland. Midwest Journal of Political Science 2:200-18.

Teorell, Jan, Sören Holmberg, and Bo Rothstein. 2008. The Quality of Government Dataset, version 15 May 2008. University of Gothenburg: The Quality of Government Institute. http://www.qog.pol.gu.se.

Vreeland, James Raymond. 2008. The effect of political regime on civil war: Unpacking anocracy. Journal of Conflict Resolution $52: 401-25$.

Wright, Joseph. 2008. How authoritarian time horizons impact foreign aid effectiveness. Comparative Political Studies 41:971-1000. 